\title{
HEART-TYPE FATTY ACID-BINDING PROTEIN (H-FABP), PENTRAXIN-3 (PTX-3) AND THROMBOMODULIN IN BOVINE TRAUMATIC PERICARDITIS
}

\author{
Ramazan YILDIZ ${ }^{1 *}$, Mahmut $\mathrm{OK}^{2}$, Merve IDER ${ }^{2}$, Ugur AYDOGDU $^{3}$ and Alper ERTÜRK ${ }^{4}$ \\ ${ }^{1}$ Department of Internal Medicine, Faculty of Veterinary Medicine, Mehmet Akif Ersoy \\ University, 15030, Burdur, Turkey; ${ }^{2}$ Department of Internal Medicine, Faculty of \\ Veterinary Medicine, Selcuk University, Konya, Turkey; ${ }^{3}$ Department of Internal \\ Medicine, Faculty of Veterinary Medicine, Balikesir University, Balikesir, Turkey; \\ ${ }^{4}$ Department of Internal Medicine, Faculty of Veterinary Medicine, Mustafa Kemal \\ University, Hatay, Turkey
}

(Received 24 June 2019; accepted 16 August 2019)

\begin{abstract}
The aim of this study was to evaluate the biomarkers of cardiac damage such as heart-type fatty acid-binding protein (H-FABP), pentraxin-3 (PTX-3), and thrombomodulin (TM) for the detection and prognosis of bovine traumatic pericarditis (TP). Spontaneous TP was diagnosed on the basis of history, clinical signs, complete blood count, glutaraldehyde test, ultrasonography, and pericardiocentesis findings. H-FABP, PTX-3 and TM levels in serum were compared between 25 Holstein cows diagnosed with spontaneous TP and 10 healthy control cows using bovine-specific ELISA kits. Serum H-FABP in cattle with TP was significantly $(\mathrm{P}<0.05)$ higher than in the control group and positively correlated with cardiac troponin-I (cTnI), creatine kinase myocardial band (CK-MB), PTX-3 and TM $(\mathrm{r}=0.683,0.342,0.448$ and 0.424 , respectively; $\mathrm{P}<0.05)$. The serum levels of PTX-3 $(\mathrm{P}<0.05)$ and TM $(\mathrm{P}<0.05)$ in cattle with TP were significantly higher than in the control group. Cardiac damage biomarkers H-FABP, PTX-3 and TM may be useful in the diagnosis of bovine TP.
\end{abstract}

Key words: Biomarker, heart-type fatty acid-binding protein (H-FABP), pentraxin-3 (PTX-3), thrombomodulin, traumatic pericarditis

Traumatic pericarditis (TP) in cattle is caused when a sharp foreign body present in the reticulum perforates the reticulum and the pericardium, resulting in the collection of serous and fibrinous inflammatory products in the pericardial sac. As a result, toxaemia and congestive heart failure develop in cattle (Gründer, 2002). The condition is diagnosed in advanced cases by findings such as oedema in the brisket region as well as bilateral jugular venous distension and/or pulsation (Gründer, 2002; Braun, 2009). However, characteristic findings are not always observed in the early phases and the same findings may occur in other dis-

*Corresponding author; E-mail: ramazanyildiz@mehmetakif.edu.tr;

Phone: 0090 (248) 213-2207; Fax: 0090 (248) 213-2001 
eases that affect the heart, such as infectious endocarditis. The clinical diagnosis of bovine TP is difficult and usually made on the basis of clinical signs alone (Mellanby et al., 2009). Radiography and echocardiography may be useful additional tests but are not widely available in veterinary practice and are often expensive and impractical (Mellanby et al., 2009). Early and accurate diagnosis is important because the prognosis in cattle with chronic suppurative pericarditis is very poor (Mellanby et al., 2009). Additional tests such as cardiac biomarkers could be useful for the diagnosis of TP.

Heart-type fatty acid-binding protein (H-FABP) is a low molecular weight, fatty acid carrying protein present in the cytoplasm of cardiomyocytes. It regulates the mitochondrial beta-oxidation system in cardiac cells, and $10 \%$ of cardiac myocyte cytosolic proteins are H-FABP (Başar et al., 2013). H-FABP is a more reliable biomarker than myoglobin and cardiac troponins for the diagnosis of acute coronary syndrome (ACS) in people (Ishii et al., 1997; Ishii et al., 2005). Release from damaged myocardial tissue leads to an increase in serum concentrations (Başar et al., 2013). The troponin complex binds to tropomyosin which is present in the contractile actin filaments of the striated muscle. Cardiac troponin I (cTnI) is one of the troponin subunits that control the binding of myosin to actin filaments (Strauss et al., 2010). Creatine kinase myocardial band (CK-MB) is an isoenzyme of creatine kinase that is abundant in the heart and is widely accepted as an indicator of myocyte damage (Yazar et al., 2002). Troponins and CK-MB are reported as biomarkers in cattle with cardiovascular disease (Yazar et al., 2002; Mellanby et al., 2007; Mellanby et al., 2009); however, we did not find studies on H-FABP as a biomarker in cattle with cardiovascular or other diseases.

Pentraxins associated with acute immune-inflammatory responses are divided into two types: short pentraxins such as $\mathrm{C}$-reactive protein (CRP) and long pentraxins such as pentraxin-3 (PTX-3) (Garlanda et al., 2005). Increased plasma CRP levels in people predict hospitalisation for heart failure independent of baseline heart failure, medication use, or coronary heart disease severity (Williams et al., 2008). PTX-3 is involved in various cellular functions, including cell adhesion, angiogenesis, inflammation and tumourigenesis, and its effect is based on modulation of the cardiovascular system (Bottazzi et al., 2016).

Thrombomodulin (TM) is produced mainly in endothelial cells and converts thrombin into an anticoagulant capable of activating protein $\mathrm{C}$ (Savchenko et al., 2008). Activated leukocytes or the products of oxidative stress cause proteolytic degradation of endothelial cells, releasing TM into the serum (Boehme et al., 2002). An elevated soluble TM level has also been found to be associated with sepsis-induced disseminated intravascular coagulation or multiple organ dysfunction syndromes (MODS) (Lin et al., 2008).

We hypothesised that the measurement of H-FABP, PTX-3, and TM might serve as a non-invasive and cost-effective replacement for traditional cardiac markers such as serum cTnI (Mellanby et al., 2007). We aimed to determine the association of H-FABP, PTX-3, and TM levels with the presence of TP in cattle. 


\section{Materials and methods}

\section{Animals}

We included 25 Holstein cows with TP (pericarditis group) and 10 healthy Holstein cows (control group) aged 2-4 years. The TP animals originating from local small dairy farms were admitted to the Large Animal Hospital of the Faculty of Veterinary Medicine of Selcuk University. The duration of the study was approximately 14 months. The occurrence of TP in all cases was spontaneous. Control cows were from the Veterinary Faculty Research and Application Farm of Selcuk University and sampled in the first months of the study. The Ethics Committee of the Veterinary Faculty of Selcuk University approved the study protocol.

\section{Clinical examination}

Physical examination included evaluation of respiratory rate, temperature, and heart rate. TP was tentatively diagnosed based on history and clinical signs including distension of jugular veins, tachycardia [slightly increased at $81-90$ beats per min (bpm), moderately increased at 91-99 bpm, and greatly increased if $\geq 100 \mathrm{bpm}$ ] (Braun et al., 2007), markedly muffled heart sounds, pericardial splashing, presence of throat, brisket or ventral abdominal oedema, complete blood count (CBC), glutaraldehyde test results, and ultrasonographic and pericardiocentesis findings (Braun et al., 2007; Braun, 2009). The area from the third to fifth intercostal spaces of the cardiac region on both sides of the thorax of the standing cows was used for ultrasonographic examination (DC-6 Vet Diagnostic Imaging System; Shenzhen Mindray, China) equipped with a real-time 3.5- and 5.0-MHz convex transducer probe. Pain tests were conducted according to previously described methods (Braun et al., 2001). At autopsy, the regions of the heart and reticulum were examined by a veterinarian to confirm the diagnosis. We included only the animals with confirmed TP.

The health of cattle in the control group from the Veterinary Faculty Research and Application Farm of Selcuk University was confirmed by physical examination, normal $\mathrm{CBC}$, glutaraldehyde test, and ultrasonographic examination.

\section{Blood sampling and laboratory analysis}

EDTA blood samples and blood without anticoagulant were collected from all cows directly into appropriate tubes through a catheter in the right jugular vein. Samples were allowed to clot at room temperature for $15 \mathrm{~min}$ and then centrifuged for $10 \mathrm{~min}$ at $2500 \times \mathrm{g}$. Serum was harvested and stored at $-80^{\circ} \mathrm{C}$ for 16 months until analysis. Previous studies had not specified a storage time that would significantly affect fatty acid-binding proteins (FABPS) over a medi- 
an of 18 months (Liu et al., 2016). For the pentraxin family such as CRP serum samples were stored at $-80^{\circ} \mathrm{C}$ (Jansen et al., 2015).

An automated $\mathrm{CBC}$ was performed (MS4e analyzer; Melet Schloesing Laboratories, Osny, France) within 30 min of sample collection. Blood smears were not reviewed.

A whole blood glutaraldehyde coagulation test (GT) was used for the semi-quantitative determination of fibrinogen and immunoglobulin. The test was performed immediately after blood collection by adding equal amounts of venous blood from the tube without anticoagulant into a tube previously prepared with $1.4 \%$ glutaraldehyde solution (Merck Schuchardt, Hohenbrunn, Germany), slowly rotating the tube to mix the sample, and noting the time required for clotting. A clotting time of $>15$ min was accepted as normal. The indications of inflammation for the clotting time were accepted as indications of severe $(0-5 \mathrm{~min})$, moderate (5-10 $\mathrm{min})$, or mild (10-15 $\mathrm{min})$ (Gokce et al., 2007).

Serum concentrations of H-FABP, TM, and PTX-3 were determined using validated commercial bovine-specific enzyme-linked immunosorbent assay (ELISA) kits according to the manufacturer's instructions (MyBioSource, San Diego, CA). The reported intra-assay and inter-assay coefficients of variation (CV) for H-FABP were $\leq 15 \%$ and $\leq 15 \%$, respectively, with a minimum detectable concentration (MDC) of $0.5 \mathrm{ng} / \mathrm{mL}$. The reported TM intra-assay and interassay CV were $\leq 5.5 \%$ and $\leq 9.1 \%$, respectively, with an $\mathrm{MDC}$ of $0.156 \mathrm{ng} / \mathrm{mL}$. The PTX-3 reported intra-assay and inter-assay CV were $\leq 15 \%$ and $\leq 15 \%$, respectively, and MDC was $0.25 \mathrm{ng} / \mathrm{mL}$. Absorbance was recorded using a microplate reader (ELx800, United States) and standard curves were generated. A chemiluminescence assay system (Siemens ADVIA Centaur XP; Erlangen, Germany) was used for the detection of serum cTn-I (Siemens catalogue 2790309) and CK-MB (Siemens catalogue 7516647). The calibration of the analyser was performed with human cTnI standards (ADVIA Centaur Calibrator UL, Siemens Medical Solutions Diagnostics). In addition, we calculated the precision of measurement with independent measurements on the ADVIA centaur device, like in the study of Varga et al. (2009). Moreover, the intra-day and inter-day precision were determined by three replicate analyses of samples taken from cattle in the control $(n=3)$ and the traumatic pericarditis (TP) groups $(n=3)$ within 1 day or on 3 consecutive days. The precision was determined by the coefficient of variation $[(\mathrm{CV} \%=100 \times(\mathrm{SD} /$ mean $)]$. The per cent coefficients of variation calculated for intraday and inter-day precision were $<7.0 \%$ and $<5.0 \%$, respectively. The ADVIA Centaur has been used reliably for the determination of serum cTnI concentration in cattle (Varga et al., 2009).

\section{Statistical analysis}

The mean and standard error of the mean (mean \pm SEM) were calculated for each parameter. The Kolmogorov-Smirnov test was used to evaluate the data 
for normality; all parameters were normally distributed. An independent student $t$-test (2-tailed) was used to determine parameter differences between healthy and TP cows. The Pearson correlation coefficient was used to quantify the relationship between H-FABP, PTX-3, thrombomodulin, cTnI, and CK-MB. SPSS software for Windows (14.01; SPSS, Chicago, IL) was employed for statistical analyses. $\mathrm{P}<0.05$ was considered statistically significant.

\section{Results}

\section{Clinical examination and ultrasound findings}

Cows with TP had no or decreased appetite and a sharp decrease in milk production as reported by owners. Clinical examination revealed a poor general condition $(n=24)$, decreased $(n=12)$ or absent $(n=13)$ ruminal motility, and decreased appetite in all animals. The animals showed signs of pain such as bruxism $(\mathrm{n}=12)$ and respiratory grunts on tracheal auscultation $(\mathrm{n}=11)$. Pain tests were positive in all animals. Twenty-one of $25 \mathrm{TP}$ animals were reluctant to walk.

The heart rate was statistically higher $(\mathrm{P}<0.05)$ in the TP group than in the control group (Table 1). Heart rate was mildly increased in 12 of 25 cows, moderately increased in 6 of 25 cows, greatly increased in 6 of 25 cows, and normal in 1 of 25 TP cows. Heart sounds were muffled in all 25 TP cows and pericardial fluid splashing sounds were audible in 13 cows. Both jugular veins were distended in all animals; throat, brisket and ventral abdomen were oedematous in 13 of 25 cases. Fifteen cows stood with their elbows abducted. The mean rectal temperature $(\mathrm{P}<0.05)$ and respiratory rate $(\mathrm{P}<0.05)$ were higher in the TP group than in the control group (Table 1). The rectal temperatures were 37.5$39.9^{\circ} \mathrm{C}$ (Table 1) and $>39.0^{\circ} \mathrm{C}$ in $15 \mathrm{TP}$ cows. The respiratory rate was $>30$ breaths/min in $17 \mathrm{TP}$ cows.

Ultrasound findings were consistent with a previously reported study (Braun, 2009). In 23 of 25 cases, a large amount of hypoechogenic fluid was observed, sometimes with a fibrin mesh floating in the pericardial sac which was later validated in postmortem findings (Fig. 1).

\section{$C B C$ and glutaraldehyde test}

White blood cell (WBC) and granulocyte (GRA) counts were significantly higher $(\mathrm{P}<0.05)$ in cattle with TP (Table 1$)$. Twenty-four animals had leukocytosis (Table 1); the total leukocyte count was $>20.0 \times 10^{9} / \mathrm{L}$ in 10 animals. Three animals had anaemia and one had thrombocytopenia. 
Table 1

Haematological parameters, glutaraldehyde coagulation test and clinical findings in 25 cows with traumatic pericarditis and 10 healthy cows (mean \pm standard error)

\begin{tabular}{|c|c|c|}
\hline Parameters & Pericarditis $(\mathrm{n}=25)$ & Control $(n=10)$ \\
\hline White blood cells $\left(\times 10^{9} / \mathrm{L}\right)^{*}$ & $19.5 \pm 1.89$ & $9.33 \pm 0.58$ \\
\hline Lymphocytes $\left(\times 10^{9} / \mathrm{L}\right)$ & $4.6 \pm 0.6$ & $3.7 \pm 0.6$ \\
\hline Monocytes $\left(\times 10^{9} / \mathrm{L}\right)$ & $0.5 \pm 0.1$ & $0.4 \pm 0.0$ \\
\hline Granulocytes $\left(\times 10^{9} / \mathrm{L}\right)^{*}$ & $14.5 \pm 1.5$ & $5.3 \pm 0.8$ \\
\hline Erythrocytes $\left(\times 10^{12} / \mathrm{L}\right)^{*}$ & $6.33 \pm 0.22$ & $7.92 \pm 0.42$ \\
\hline Haematocrit $(\%)^{*}$ & $27.7 \pm 1.25$ & $36.1 \pm 1.56$ \\
\hline Platelets $\left(\times 10^{9} / \mathrm{L}\right)$ & $322 \pm 39.0$ & $411 \pm 38.1$ \\
\hline Glutaraldehyde test (min) & $2.88 \pm 0.28$ & $>15$ \\
\hline Rectal temperature $\left({ }^{\circ} \mathrm{C}\right)^{*}$ & $38.8 \pm 0.16$ & $38.2 \pm 0.08$ \\
\hline Heart rate (beats $/ \mathrm{min})^{*}$ & $94.4 \pm 3.30$ & $69.4 \pm 1.68$ \\
\hline Respiratory rate $^{*}$ (breaths/min) & $37.3 \pm 1.87$ & $25.2 \pm 0.20$ \\
\hline
\end{tabular}

*Statistically significant difference between groups at $\mathrm{P}<0.05$

The glutaraldehyde test (GA) was positive in all TP animals. Clotting time for GA was moderately decreased (3-6 min) in 5 animals and severely decreased $(<3 \mathrm{~min})$ in 20 animals.

\section{Biomarkers}

The serum levels of H-FABP in cattle with TP were significantly $(\mathrm{P}<$ 0.05) higher than in the control group (Fig. 2) and significantly correlated with cTnI, CK-MB, PTX-3, and TM with a Pearson correlation coefficient of 0.683, $0.342,0.448$ and 0.424 , respectively $(\mathrm{P}<0.05$; Table 2$)$. The serum levels of cTnI $(\mathrm{P}<0.05)$ and CK-MB $(\mathrm{P}<0.05)$ in cattle with TP were significantly higher than in the control group (Fig. 2). The serum levels of PTX-3 $(\mathrm{P}<0.05)$ and TM $(\mathrm{P}<0.05)$ in cattle with TP were significantly higher than in the control group (Fig. 2) and significantly correlated with H-FABP, with a Pearson correlation coefficient of 0.448 and 0.424 , respectively $(\mathrm{P}<0.05$; Table 2$)$.

\section{Discussion}

To the best of our knowledge, this is the first report which shows the increase of novel cardiac biomarkers (H-FABP, PTX-3, and TM) and their correlation with cTnI and CK-MB in cattle with TP. A previous study reported that $\mathrm{H}$ FABP is a potentially independent marker of cardiac cases and has higher predictive capacity than cTnT at the onset of ACS (Ishii et al., 2005). The high serum levels of H-FABP and their correlation with cTnI and CK-MB (Table 2, Fig. 2) 
in cattle with TP in our study may indicate that H-FABP can be used for the detection of cardiac damage in cattle. An increase in cTn-I and H-FABP in dogs treated with formoterol was found to be more sensitive than creatine kinase, lactate dehydrogenase, and CK-MB activity in detecting drug-induced cardiac injury in dogs (Strauss et al., 2010). Increased levels of H-FABP were observed in the plasma of mice (Aartsen et al., 2000) and in the urine of rats (Volders et al., 1993) after experimentally induced myocardial infarction. Cattle with pericardial disease had a higher serum cTnI concentration than healthy cattle, but cTnI could not be used to differentiate pericarditis from other cardiac diseases (Mellanby et al., 2009). The findings of these studies suggest that H-FABP and similar markers may be needed in the veterinary field.

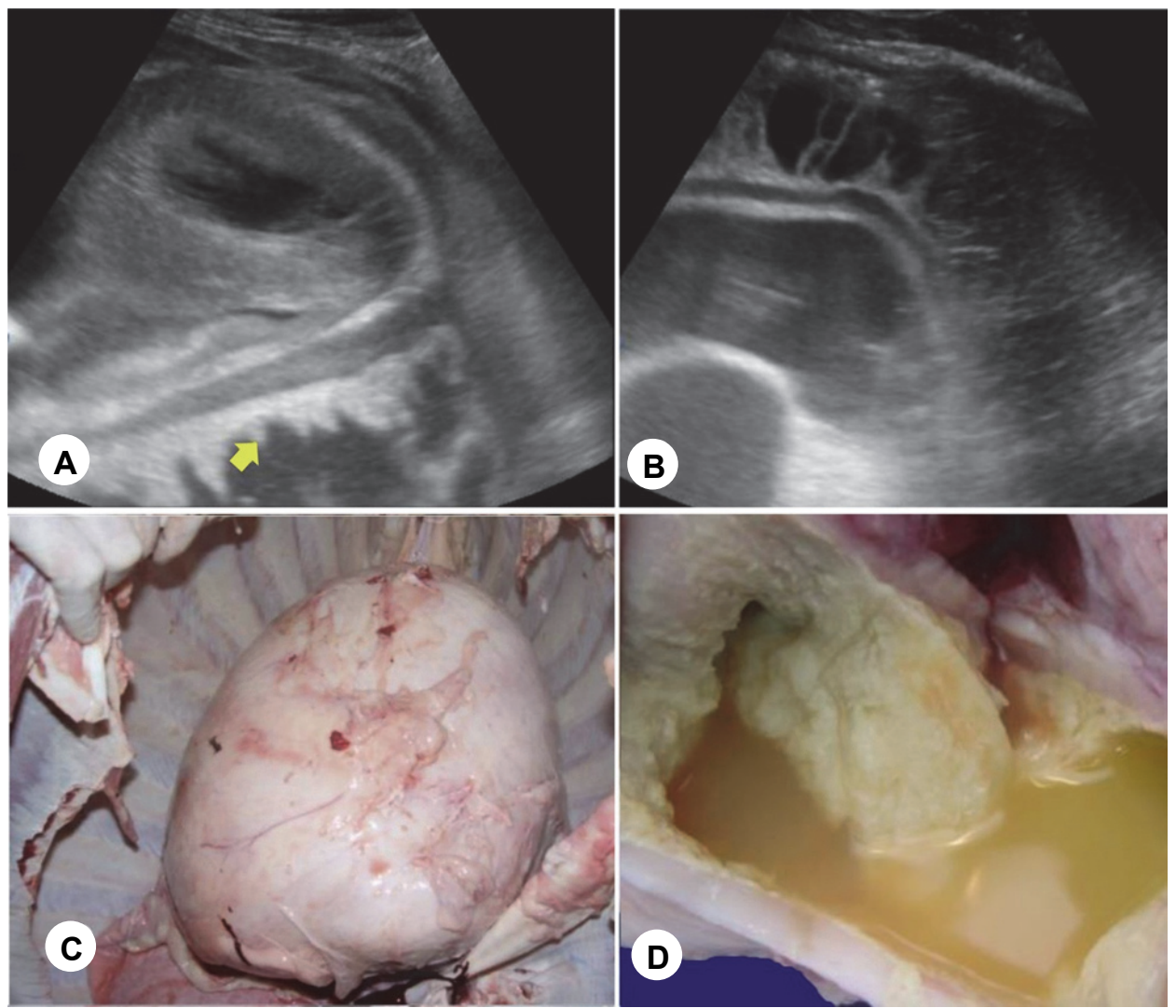

Fig. 1. Ultrasonographic and postmortem appearance of traumatic pericarditis (TP) in a cow. A: Ultrasonogram with thickening of the pericardium and pericardial sac with fibrin mesh (yellow arrow). B: Ultrasonogram with pericardial effusion, pericardial sac and a fibrin mesh. A $3.5 \mathrm{MHz}$ convex transducer probe was placed in the fifth intercostal space on the left side to obtain images. C: Gross postmortem findings with a defective heart shaped like a ball. D: Pericardial sac of a cow with traumatic pericarditis, covered with a yellow fibrin mesh and fluid 


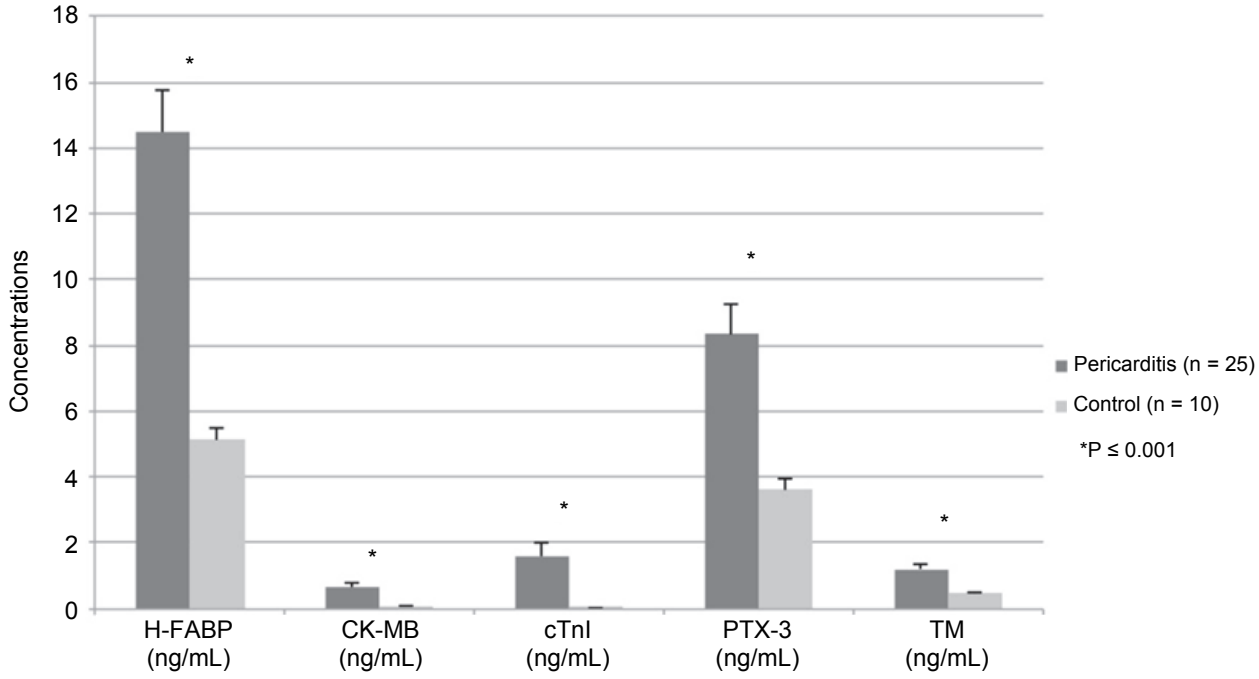

$\mathrm{H}-\mathrm{FABP}=$ heart-type fatty acid-binding protein; $\mathrm{CK}-\mathrm{MB}=$ creatine kinase myocardial band; $\mathrm{cTnl}=$ cardiac troponin-I; PTX-3 = pentraxin-3; TM = thrombomodulin

Fig. 2. Heart-type fatty acid-binding protein, pentraxin-3, thrombomodulin, cardiac troponin and creatine kinase myocardial band levels in 25 cows with traumatic pericarditis and 10 healthy cows $($ mean \pm SEM)

Table 2

Pearson correlation coefficient between H-FABP, PTX-3, TM, cTnI and CK-MB in 25 cows with traumatic pericarditis and 10 healthy cows $(n=35)$

\begin{tabular}{lcccc}
\hline Parameters $(\mathrm{n}=35)$ & $\mathrm{cTnI}(\mathrm{ng} / \mathrm{mL})$ & CK-MB $(\mathrm{ng} / \mathrm{mL})$ & PTX-3 $(\mathrm{ng} / \mathrm{mL})$ & TM $(\mathrm{ng} / \mathrm{mL})$ \\
\hline H-FABP $(\mathrm{ng} / \mathrm{mL})$ & $0.683^{* *}$ & $0.342^{*}$ & $0.448^{* *}$ & $0.424^{*}$ \\
cTnI $(\mathrm{ng} / \mathrm{mL})$ & 1 & 0.237 & $0.430^{*}$ & 0.334 \\
CK-MB $(\mathrm{ng} / \mathrm{mL})$ & & 1 & 0.175 & 0.091 \\
PTX-3 $(\mathrm{ng} / \mathrm{mL})$ & & & 1 & 0.106
\end{tabular}

$\mathrm{H}-\mathrm{FABP}=$ heart-type fatty acid-binding protein; cTnI = cardiac troponin-I; CK-MB $=$ creatine kinase myocardial band; PTX-3 = pentraxin-3; TM = thrombomodulin; ${ }^{*}$ Significant correlation at $\mathrm{P}<0.05 ;{ }^{* *}$ Significant correlation at $\mathrm{P}<0.01$

Pericarditis is an inflammation of the pericardium with an accumulation of serous or fibrinous exudate (Gründer, 2002), as shown in Fig. 1. Leukocytosis and hyperfibrinogenaemia are also common findings that indicate severe inflammation in cattle with TP (Braun, 2009). Hyperfibrinogenaemia shows an acute phase response in cattle with TP, and coagulation abnormalities may also be seen in TP (Gokce et al., 2007; Tothova et al., 2014). In this study, the increased levels of PTX-3 and TM are probably related to the acute phase response and inflammatory state (Tothova et al., 2014) and the coagulation abnormalities 
such as endothelial dysfunction (Gokce et al., 2007) in cattle with TP. The generation of inflammatory signals stimulates the production of PTX-3 in various cell types (Savchenko et al., 2008). Under resting conditions, PXT-3 is excreted in cardiomyocytes; however, human and mouse studies revealed that its production is further increased in the early phase of myocardial ischemia (Maugeri et al., 2011). The attachment of PTX-3 to P-selectin reduces neutrophil infiltration in the area of myocardial damage (Deban et al., 2010), whereas its binding to the active thrombocytes reduces proinflammatory and prothrombotic effects in patients with myocardial damage (Maugeri et al., 2011). This is evident from a significantly high myocardial injury observed in PTX-3-deficient mice compared with the controls (wild-type) (Salio et al., 2008). It has been reported that the plasma concentrations of PTX-3 significantly increase in patients with heart failure (HF) and positively correlate with brain natriuretic peptide and echocardiographic findings (Casula et al., 2017). Thus, in left ventricular diastolic dysfunction and HF with a normal ejection fraction, PTX-3 has been reported as an independent inflammatory marker (Matsubara et al., 2011).

Many studies indicate that elevated TM levels are associated with a severe inflammatory state (Chao et al., 2004; Arazi et al., 2011) and increased mortality in conditions such as ACS, trauma, and MODS (Lin et al., 2008; Arazi et al., 2011). The damage caused by activated leukocytes results in the release of soluble thrombomodulin (sTM) by proteolytic degradation of endothelial cells (Boehme et al., 2002). After the percutaneous coronary intervention, an association between CRP and soluble TM levels is indicative of a relationship between elevated TM levels and inflammation and myocardial damage (Chao et al., 2004), indicating that TM has anti-inflammatory properties (Conway et al., 2002).

In this study, the serum levels of PTX-3 and TM in cattle with TP were significantly higher than in the control group and significantly correlated with $\mathrm{H}$ FABP (Table 2, Fig. 2). The changes observed in PTX-3 suggest myocardial damage (Maugeri et al., 2011) and acute phase response (Bottazzi et al., 2006; Savchenko et al., 2008). 'PTX-3 may reflect local inflammatory status in the cardiovascular system' and thus may be a potential novel biomarker of inflammation (Liu et al., 2015). Elevated TM may have pathophysiological importance in cattle with TP associated with early leukocyte activation and endothelial release (Arazi et al., 2011), haemostatic activation (Kim et al., 2016) or inflammation and myocardial damage (Chao et al., 2004).

H-FABP, which is used as a rapid diagnostic tool for heart failure in humans, may be useful for the identification of TP in cattle. PTX-3 has the clinical potential to be used like CRP in human medicine and may be a cost-effective diagnostic option in veterinary fields in the future. However, there are several limitations to our study. Histopathology was not performed to correlate the amount of myocardial damage with levels of PTX-3, H-FABP or TM, to gauge how well they indicate in vivo heart disease. The cattle had the natural disease in suffi- 
ciently advanced stages of TP to show clinical signs and require veterinary attention; therefore the usefulness of these biomarkers as early indicators of preclinical disease is unknown. As cattle with other cardiac conditions were not included in this study, the ability of these biomarkers to discriminate between TP and other cardiac or pericardial diseases is also not known. In order to evaluate these markers in early diagnosis, experimental studies are needed. These markers also need to be more economical for routine clinical use in cattle. Future studies are warranted on the changes of levels of these biomarkers as prognostic and mortality indicators in non-traumatic and traumatic heart diseases of cattle. The sensitivity and specificity of H-FABP and PTX-3 assays in distinguishing cattle with TP from other inflammatory or cardiovascular diseases should be evaluated.

\section{References}

Aartsen, W. M., Pelsers, M. M., Hermens, W. T., Glatz, J. F., Daemen, M. J. and Smits, J. F. (2000): Heart fatty acid-binding protein and cardiac troponin T plasma concentrations as markers for myocardial infarction after coronary artery ligation in mice. Pflugers. Arch. 439, 416-422.

Arazi, H., Giorgi, M., Miriuka, S., Caroli, C. and Carnevalini, M. (2011): Soluble thrombomodulin levels are related to inflammation after coronary bypass surgery. J. Clin. Cardiol. 2, 165.

Başar, O., Akbal, E., Köklü, S., Tuna, Y., Koçak, E., Başar, N., Tok, D., Erbiş, H. and Senes, M. (2013): Increased H-FABP concentrations in nonalcoholic fatty liver disease. Possible marker for subclinical myocardial damage and subclinical atherosclerosis. Herz. 38, 417-422.

Boehme, M. W., Galle, P. and Stremmel, W. (2002): Kinetics of thrombomodulin release and endothelial cell injury by neutrophil-derived proteases and oxygen radicals. Immunology 107, 340-349.

Bottazzi, B., Bastone, A., Doni, A., Garlanda, C., Valentino, S., Deban, L., Maina, V., Cotena, A., Moalli, F., Vago, L., Salustri, A., Romani, L. and Mantovani, A. (2006): The long pentraxin PTX3 as a link among innate immunity, inflammation, and female fertility. J. Leukoc. Biol. 79, 909-912.

Bottazzi, B., Inforzato, A., Messa, M., Barbagallo, M., Magrini, E., Garlanda, C. and Mantovani, A. (2016): The pentraxins PTX3 and SAP in innate immunity, regulation of inflammation and tissue remodelling. J. Hepatol. 64, 1416-1427.

Braun, U. (2009): Traumatic pericarditis in cattle: clinical, radiographic and ultrasonographic findings. Vet. J. 182, 176-186.

Braun, U., Lejeune, B., Schweizer, G., Puorger, M. and Ehrensperger, F. (2007): Clinical findings in 28 cattle with traumatic pericarditis. Vet. Rec. 161, 558-563.

Braun, U., Schweizer, T. and Pusterla, N. (2001): Echocardiography of the normal bovine heart: technique and ultrasonographic appearance. Vet. Rec. 148, 47-51.

Casula, M., Montecucco, F., Bonaventura, A., Liberale, L., Vecchié, A., Dallegri, F. and Carbone, F. (2017): Update on the role of pentraxin 3 in atherosclerosis and cardiovascular diseases. Vascul. Pharmacol. 99, 1-12.

Chao, T. H., Li, Y. H., Tsai, W. C., Chen, J. H., Liu, P. Y. and Tsai, L. M. (2004): Elevation of the soluble thrombomodulin levels is associated with inflammation after percutaneous coronary interventions. Clin. Cardiol. 27, 407-410. 
Conway, E. M., Van de Wouwer, M., Pollefeyt, S., Jurk, K., Van Aken, H., De Vriese, A., Weitz, J. I., Weiler, H., Hellings, P. W., Schaeffer, P., Herbert, J. M., Collen, D. and Theilmeier, G. (2002): The lectin-like domain of thrombomodulin confers protection from neutrophilmediated tissue damage by suppressing adhesion molecule expression via nuclear factor kappaB and mitogen-activated protein kinase pathways. J. Exp. Med. 196, 565-577.

Deban, L., Russo, R. C., Sironi, M., Moalli, F., Scanziani, M., Zambelli, V., Cuccovillo, I., Bastone, A., Gobbi, M., Valentino, S., Doni, A., Garlanda, C., Danese, S., Salvatori, G., Sassano, M., Evangelista, V., Rossi, B., Zenaro, E., Constantin, G., Laudanna, C., Bottazzi, B. and Mantovani, A. (2010): Regulation of leukocyte recruitment by the long pentraxin PTX3. Nat. Immunol. 11, 328-334.

Garlanda, C., Bottazzi, B., Bastone, A. and Mantovani, A. (2005): Pentraxins at the crossroads between innate immunity, inflammation, matrix deposition, and female fertility. Annu. Rev. Immunol. 23, 337-366.

Gokce, H. I., Gokce, G. and Cihan, M. (2007): Alterations in coagulation profiles and biochemical and haematological parameters in cattle with traumatic reticulo peritonitis. Vet. Res. Commun. 31, 529-537.

Gründer, H. D. (2002): Innere Medizin und Chirurgie des Rindes. Parey Buchverlag, Berlin and Germany.

Ishii, J., Ozaki, Y., Lu, J., Kitagawa, F., Kuno, T., Nakano, T., Nakamura, Y., Naruse, H., Mori, Y., Matsui, S., Oshima, H., Nomura, M., Ezaki, K. and Hishida, H. (2005): Prognostic value of serum concentration of heart-type fatty acid-binding protein relative to cardiac troponin $\mathrm{T}$ on admission in the early hours of acute coronary syndrome. Clin. Chem. 51, $1397-1404$

Ishii, J., Wang, J. H., Naruse, H., Taga, S., Kinoshita, M., Kurokawa, H., Iwase, M., Kondo, T., Nomura, M., Nagamura, Y., Watanabe, Y., Hishida, H., Tanaka, T. and Kawamura, K. (1997): Serum concentrations of myoglobin vs. human heart-type cytoplasmic fatty acidbinding protein in early detection of acute myocardial infarction. Clin. Chem. 43, 1372-1378.

Jansen, E., Beekhof, P., Viezeliene, D., Muzakova, V. and Skalicky, J. (2015): Long-term stability of cancer biomarkers in human serum: biomarkers of oxidative stress and redox status, homocysteine, CRP and the enzymes ALT and GGT. Biomark. Med. 9, 425-432.

Kim, S. D., Baker, P., DeLay, J. and Wood, R. D. (2016): Thrombomodulin expression in tissues from dogs with systemic inflammatory disease. Vet. Pathol. 53, 797-802.

Lin, S. M., Wang, Y. M., Lin, H. C., Lee, K. Y., Huang, C. D., Liu, C. Y., Wang, C. H. and Kuo, H. P. (2008): Serum thrombomodulin level relates to the clinical course of disseminated intravascular coagulation, multiorgan dysfunction syndrome, and mortality in patients with sepsis. Crit. Care Med. 36, 683-689.

Liu, H., Guo, X., Yao, K., Wang, C., Chen, G., Gao, W., Yuan, J., Yu, W. and Ge, J. (2015): Pentraxin-3 predicts long-term cardiac events in patients with chronic heart failure. Biomed. Res. Int. 817615, 20.

Liu, K. D., Siew, E. D., Reeves, W. B., Himmelfarb, J., Go, A. S., Hsu, C. Y., Bennett, M. R., Devarajan, P., Ikizler, T. A., Kaufman, J. S., Kimmel, P. L., Chinchilli, V. M. and Parikh, C. R. (2016): Storage time and urine biomarker levels in the ASSESS-AKI study. PLoS One 11, e0164832.

Matsubara, J., Sugiyama, S., Nozaki, T., Sugamura, K., Konishi, M., Ohba, K., Matsuzawa, Y., Akiyama, E., Yamamoto, E., Sakamoto, K., Nagayoshi, Y., Kaikita, K., Sumida, H., KimMitsuyama, S. and Ogawa, H. (2011): Pentraxin 3 is a new inflammatory marker correlated with left ventricular diastolic dysfunction and heart failure with normal ejection fraction. J. Am. Coll. Cardiol. 57, 861-869.

Maugeri, N., Rovere-Querini, P., Slavich, M., Coppi, G., Doni, A., Bottazzi, B., Garlanda, C., Cianflone, D., Maseri, A., Mantovani, A. and Manfredi, A. A. (2011): Early and transient release of leukocyte pentraxin 3 during acute myocardial infarction. J. Immunol. 187, 970-979. 
Mellanby, R. J., Henry, J. P., Cash, R., Ricketts, S. W., Bexiga, J. R. and Mellor, D. J. (2007): Serum cardiac troponin I concentrations in cattle with pericarditis. Vet. Rec. 161, 454-455.

Mellanby, R. J., Henry, J. P., Cash, R., Ricketts, S. W., Bexiga, R., Truyers, I. and Mellor, D. J. (2009): Serum cardiac troponin I concentrations in cattle with cardiac and noncardiac disorders. J. Vet. Intern. Med. 23, 926-930.

Salio, M., Chimenti, S., De Angelis, N., Molla, F., Maina, V., Nebuloni, M., Pasqualini, F., Latini, R., Garlanda, C. and Mantovani, A. (2008): Cardio protective function of the long pentraxin PTX3 in acute myocardial infarction. Circulation 117, 1055-1064.

Savchenko, A., Imamura, M., Ohashi, R., Jiang, S., Kawasaki, T., Hasegawa, G., Emura, I., Iwanari, H., Sagara, M., Tanaka, T., Hamakubo, T., Kodama, T. and Naito, M. (2008): Expression of pentraxin 3 (PTX3) in human atherosclerotic lesions. J. Pathol. 215, 48-55.

Strauss, V., Wöhrmann, T., Frank, I., Hübel, U., Luft, J., Bode, G. and Germann, P. G. (2010): Short-term increase of serum troponin I and serum heart-type fatty acid-binding protein $(\mathrm{H}-$ FABP) in dogs following administration of formoterol. Exp. Toxicol. Pathol. 62, 343-352.

Tothova, Cs., Nagy, O. and Kovac, G. (2014): Acute phase proteins and their use in the diagnosis of diseases in ruminants: a review. Vet. Med. 59, 163-180.

Varga, A., Schober, K. E., Walker, W. L., Lakritz, J. and Michael Rings, D. (2009): Validation of a commercially available immunoassay for the measurement of bovine cardiac troponin I. J. Vet. Intern. Med. 23, 359-365.

Volders, P. G., Vork, M. M., Glatz, J. F. and Smits, J. F. (1993): Fatty acid binding proteinuria diagnosis myocardial infarction in the rat. Mol. Cell. Biochem. 123, 185-190.

Williams, E. S., Shah, S. J., Ali, S., Na, B. Y., Schiller, N. B. and Whooley, M. A. (2008): Creactive protein, diastolic dysfunction, and risk of heart failure in patients with coronary disease: Heart and Soul Study. Eur. J. Heart. Fail. 10, 63-69.

Yazar, E., Birdane, Y. O., Elmas, M., Tras, B. and Bas, A. L. (2002): Effect of tilmicosin on serum creatine kinase, creatine kinase-MB and troponin I levels in New Zealand White rabbits. Arch. Geflügelk. 66, 237-239. 